\title{
PERSEPSI MASYARAKAT TERHADAP PROGRAM PENGELOLAAN SAMPAH SECARA REDUCE, REUSE, RECYCLE (3R) DI KELURAHAN MANEMBO-NEMBO TENGAH KECAMATAN MATUARI KOTA BITUNG
}

\author{
Mario Rinaldi Malee \\ Benu Olfie L.S \\ Welson M. Wangke
}

\begin{abstract}
Perceptions in relation to the environment, namely as the process where individuals organize and interpret their sensory impressions in order to give meaning to the environment. With the perception of the attitude that it will form a stable tendency to act a certain way in certain situations. Research on the public perception is very important because by knowing that perception would help prevent the arising problems. The purpose of this research is to determine public perception to Trash Processing Program by using $3 R$ method viewed from aspects Socialization, facilities providing, and sorting, composting, and recycling by using instrument Likert scale. This research has been carried out for three months, from February until March 2016 from preparation till the preparation of research reports. Research located in the Manembo-nembo Tengah Sub District Matuari district Bitung City..This research using primary data and secondary data. Primary data obtained from 68 respondents by using questionnaires. While Secondary data obtained from Dinas Kebersihan and Menembo-nembo tengah office. Sampling method used in this research is purposive sampling. This research shows that public perception to trash processing socialization program with $3 R$ still neutral, because of the low socialization from local govern, while public perception to facilities and infrastructure providing program is positive. For public perception to sorting, composting, and trash recycling is positive. So that most of public have positive perception to trash processing socialization program with $3 R$.
\end{abstract}

Keywords: Public Perception, Solid Waste Managemeny, Manembo-nembo Tengah, Bitung City.

\begin{abstract}
ABSTRAK
Persepsi dalam kaitannya dengan lingkungan, yaitu sebagai proses dimana individu-individu mengorganisasikan dan menafsirkan kesan indera mereka agar memberi makna kepada lingkungannya. Dengan adanya persepsi maka akan terbentuk sikap yaitu suatu kecenderungan yang stabil untuk bertindak secara tertentu di dalam situasi tertentu pula. Penelitian tentang persepsi masyarakat sangat penting karena dengan mengetahui persepsi tersebut akan membantu mencegah bahkan menanggulangi dampak lingkungan hidup yang timbul. Penelitian ini bertujuan untuk mengetahui persepsi masyarakat terhadap program pengelolaan sampah secara 3R di Kelurahan Manembo-nembo Tengah dilihat dari aspek program yaitu, sosialisasi, penyediaan sarana dan prasarana, serta pemilahan, pengomposan, dan daur ulang sampah dengan menggunakan alat ukur skala likert. Penelitian ini dilaksanakan selama empat bulan yaitu dari bulan Februari sampai dengan bulan Mei tahun 2016 mulai dari persiapan sampai penyusunan laporan penelitian. Tempat penelitian adalah Kelurahan Manembo-nembo Tengah Kecamatan Matuari Kota Bitung. Penelitian ini menggunakan data primer dan data sekunder. Data primer diperoleh dari 68 responden dari masyarakat menggunakan kuisioner. Sedangkan data sekunder diperoleh dari Dinas Kebersihan dan Kantor Kelurahan Manembo-nembo Tengah. Metode pengambilan sampel dalam penelitian ini menggunakan metode purposive sampling. Penelitian ini menunjukan bahwa persepsi masyarakat terhadap sosialisasi program pengelolaan sampah secara 3R masih tergolong netral, hal ini disebabkan kurangnya sosialisasi yang dilakukan pemerintah setempat, sedangkan persepsi masyarakat terhadap penyediaan sarana dan prasarana penunjang program adalah positif. Untuk persepsi masyarakat terhadap pemilahan, pengomposan, dan daur ulang sampah adalah positif. Sehingga sebagian besar masyarakat cenderung memiliki persepsi positif terhadap program pengelolaan sampah secara $3 \mathrm{R}$.
\end{abstract}

Kata kunci: Persepsi Masyarakat, Pengelolaan Sampah, Manembo-nembo Tengah, Kota Bitung 


\section{PENDAHULUAN}

\section{Latar Belakang}

Permasalahan lingkungan hidup merupakan masalah yang akan terus berkembang dan berproses. Salah satu masalah lingkungan yang sangat dekat dengan kehidupan sehari-hari adalah masalah sampah. Berbagai hasil dari aktivitas manusia dan makin bertambahnya jumlah penduduk mengakibatkan bahan buangan makin hari makin bertambah banyak (Chandra, 2006).

Sampah seringkali menjadi persoalan rumit dalam masyarakat, sampah juga dapat menjadi peluang terjadinya pencemaran lingkungan disertai penurunan kualitas lingkungan. Oleh karena itu, diperlukan adanya pengelolaan sampah yang berwawasan lingkungan dengan tujuan utama untuk mengurangi sampah dan mendayagunakan sampah agar tidak menjadi barang yang benarbenar tidak berguna dan dibuang.

Berbagai bentuk program dibuat oleh pemerintah pusat maupun daerah bertujuan untuk mengatasi pencemaran lingkungan yang diakibatkan oleh sampah. Salah satunya program pengelolaan sampah secara 3R. Pengelolaan sampah secara Reduce, Reuse, Recycle (3R) sudah menjadi kebijakan secara nasional sejak disahkannya Undang-undang No. 18 tahun 2008 tentang Pengelolaan Sampah. Dengan menerapkan program ini, secara umum diharapkan timbulan sampah akan berkurang dari sumbernya sehingga sampah yang dibuang ke TPA juga berkurang. Di samping itu juga dapat menjadi alat dalam mengoptimalkan pemanfaatan sampah sehingga sampah memiliki nilai ekonomis dan dapat membuka lapangan pekerjaan

Pengelolaan sampah juga diterapkan di kota-kota yang ada di Sulawesi Utara, salah satunya Kota Bitung. Pemerintah Kota Bitung telah mengadakan kegiatan pengelolaan sampah secara 3R sejak ditetapkannya Peraturan Daerah Kota Bitung Nomor 17 Tahun 2013 Tentang Pengelolaan Sampah di Kota Bitung pasal 24 ayat 1 yang berbunyi setiap orang wajib memelihara kebersihan di lingkungan serta melakukan kegiatan pengurangan sampah melalui tindakan mengurangi pemakaian produk yang menghasilkan sampah (reduce), tindakan menggunakan kembali (reuse) dan mendaur ulang sampah (recycle) sehingga dilaksanakan program pengelolaan sampah secara $3 \mathrm{R}$ sejak Bulan Mei 2013.
Pemerintah Kota Bitung mewujudkannya dengan melakukan Sosialisasi Program Pengelolaan Sampah, Pengadaan Sarana dan Prasarana Kebersihan berupa TPST 3R dan Bank Sampah yang tersebar di beberapa sekolah dan kelurahan. Tempat kegiatan TPST 3R (Tempat Pengelolaan Sampah Terpadu) ini disebar di 4 kecamatan. Salah satu penempatannya di Kecamatan Matuari, Kelurahan Manembo-nembo Tengah. Tujuan dari pengadaan TPST ini yaitu adanya pemilahan sampah yang bernilai ekonomis dan bisa didaur ulang dan pembuatan kompos dari sisa-sisa sayuran, dan dari dedauan. Program pengelolaan sampah secara $3 \mathrm{R}$ ini dapat memberikan dampak positif terhadap lingkungan hidup yaitu pengurangan beban pencemar (pollutant load) yang dibuang ke lingkungan, baik pencemar air, tanah maupun udara (Anonim 2011).

Dalam kajian lingkungan hidup, persepsi merupakan dampak primer, sekunder bahkan dampak tersier. Dampak primer berasal dari kegiatan yang langsung bersentuhan dengan masyarakat misalnya kegiatan sosialisasi sedangkan dampak sekunder atau tersier merupakan dampak turunan yang diakibatkan oleh perubahan yang terjadi pada komponen fisik, kimia, dan biologi yang selanjutnya mempengaruhi persepsi masyarakat (Adiwibowo dkk dalam Wangke, 2010).

Persepsi dalam kaitannya dengan lingkungan, yaitu sebagai proses dimana individuindividu mengorganisasikan dan menafsirkan kesan indera mereka agar memberi makna kepada lingkungannya. Dengan adanya persepsi maka akan terbentuk sikap yaitu suatu kecenderungan yang stabil untuk bertindak secara tertentu di dalam situasi tertentu pula (Robbins dalam Wangke, 2010).

Penelitian tentang persepsi masyarakat sangat penting karena dengan mengetahui persepsi tersebut akan membantu mencegah bahkan menanggulangi dampak lingkungan hidup yang timbul. Jika timbul persepsi negatif terhadap suatu obyek maka orang cenderung akan bersikap menolak obyek tersebut. Sebaliknya jika timbul persepsi positif maka seseorang akan cenderung menerima atau mendukung obyek tersebut (Wangke 2010), dimana obyek yang dimaksud adalah Program Pengelolaan Sampah Secara reduce, reuse, recycle (3R). Hingga saat ini bagaimana persepsi masyarakat Kelurahan Manembo-nembo Tengah terhadap program 
tersebut masih belum jelas, oleh sebab itu penelitian ini dilaksanakan.

\section{Perumusan Masalah}

Bagaimana persepsi masyarakat terhadap program pengelolaan sampah secara Reduce, Reuse, Recycle (3R) di Kelurahan Manembo-nembo Tengah Kecamatan Matuari Kota Bitung.

\section{Tujuan Penelitian}

Tujuan dari penelitian ini, yaitu untuk mengetahui persepsi masyarakat terhadap program pengelolaan sampah secara Reduce, Reuse, Recycle (3R) di Kelurahan Manembo-nembo Tengah, Kecamatan Matuari, Kota Bitung.

\section{Manfaat Penelitian}

Manfaat dari penelitian ini, yaitu penelitian ini diharapkan dapat memberikan informasi bagi masyarakat dan instansi terkait tentang persepsi masyarakat terhadap program pengelolaan sampah secara Reduce, Reuse, Recycle (3R) di Kelurahan Manembo-nembo Tengah, Kecamatan Matuari, Kota Bitung.

\section{METODOLOGI PENELITIAN}

\section{Waktu dan Tempat Penelitian}

Penelitian ini dilaksanakan selama 3 (tiga) bulan dari Bulan Februari hingga Mei 2016. Tempat penelitian dilaksanakan di Kelurahan Manembo-nembo Tengah Kecamatan Matuari Kota Bitung.

\section{Metode Pengumpulan Data}

Penelitiaan ini menggunakan data primer dan data sekunder. Data primer diperoleh dari wawancara langsung dengan responden yaitu masyarakat yang ada di Kelurahan Manembo-nembo Tengah Kecamatan Matuari Kota Bitung. Wawancara tersebut berdasarkan daftar pertanyaan yang telah disiapkan, sedangkan data sekunder diambil dari pihak pemerintah atau instansi yang terkait dalam penelitian ini yaitu Dinas Kebersihan, dan Kantor Kelurahan Manembonembo Tengah Kecamatan Matuari Kota Bitung.

\section{Metode Pengambilan Sampel}

Pengambilan sampel menggunakan teknik purposive sampling atau teknik pengambilan sampel dengan pertimbangan tertentu (Sugiyono, 2012). Jumlah sampel yang dijadikan sebagai responden adalah 5\% dari jumlah populasi (jumlah kepala keluarga di Kelurahan Manembo-nembo Tengah 1351 KK) yaitu responden sebanyak 68 orang. Dari 68 responden tersebut dibagi pada 4 lingkungan sehingga didapat 17 responden setiap lingkungan.

\section{Konsep Pengukuran Variabel}

1. Karakteristik Responden :

a) Usia : Dalam satuan tahun

b) Jenis Kelamin : Laki-laki/Perempuan

c) Tingkat pendidikan :

a. Tidak Tamat/Tidak Besekolah

b. SD

c. SMP

d. SMA

e. Perguruan Tinggi

d) Pekerjaan

2. Persepsi:

Persepsi adalah pemaknaan masyarakat mengenai program pengelolaan sampah secara 3R. Program pengelolaan sampah secara 3R terbagi menjadi 3 aspek, yaitu :

1) Sosialisasi, dalam hal ini penyuluhan atau penyebaran informasi yang dilakukan pemerintah tentang kebijakan pengelolaan persampahan. Indikatornya sebagai berikut :

a. Materi yang dibawakan tentang TPST 3R

b. Penempatan TPST 3R

c. Penempatan tempat sampah 2 warna

d. Informasi terhadap program bank sampah

2) Penyediaan Sarana dan Prasarana, dalam hal ini fasilitas yang disediakan oleh pemerintah di lingkungan tempat tinggal masyarakat untuk menunjang program pengelolaan sampah secara 3R berupa Pengadaan Tempat Pemilahan Sampah Terpadu (TPST 3R), Bank Sampah Pro Mirah, dan Tempat Sampah 2 Warna. Indikatornya sebagai berikut : 
a. Pengadaan TPST 3R memberikan manfaat bagi lingkungan

b. Lokasi TPST 3R di tempat strategis

c. TPST 3R memberikan motivasi terhadap masyarakat dalam mengelolah sampah

d. TPST 3R mengurangi volume sampah yang dibuang ke TPA

e. Bentuk dan warna tempat sampah 2 warna

f. Ukuran tempat sampah 2 warna

g. Jumlah tempat sampah 2 warna

h. Tempat sampah 2 warna memberikan kemudahan untuk membuang sampah

i. Bank sampah memberikan manfaat bagi masyarakat

j. Bank sampah membantu perbaikan kebersiah lingkungan

$\mathrm{k}$. Bank sampah membantu mengurangi tumpukan sampah

3) Pemilahan, Pengomposan dan Daur Ulang. Indikatornya sebagai berikut:

a. Pemilahan sampah bermanfaat untuk kelestarian lingkungan hidup

b. Pemilahan sampah memberikan manfaat bagi masyarakat

c. Pengolahan sampah menjadi kompos memberikan manfaat bagi masyarakat

d. Pengolahan sampah menjadi kerajinan memberikan manfaat bagi masyarakat.

\section{Metode Analisis Data}

Analisis data yang digunakan dalam penelitian ini adalah analisis deskriptif yang setiap jawaban atau tanggapan responden diukur dengan menggunakan metode Skala Likert yang dibuat dalam bentuk tabel checklist. Menurut Sugiyono (2012), Skala Likert digunakan untuk mengukur sikap, pendapat, dan persepsi seseorang atau sekelompok orang tentang fenomena sosial. Fenomena sosial ini telah ditetapkan secara spesifik oleh peneliti, yang selanjutnya disebut sebagai variabel penelitian. Variabel yang akan diukur dijabarkan menjadi indikator variabel kemudian indikator tersebut dijadikan menjadi titik tolak untuk menyusun item-item instrumen yang dapat berupa pernyataan atau pertanyaan.

Dalam penelitian ini disusun 20 pernyataan, selanjutnya jawaban atau tanggapan responden terhadap pernyataan tersebut diberi penilaian dengan menggunakan skor. Setiap jawaban dihubungkan dengan pernyataan yang diungkapkan dengan kata-kata berikut:

a. Sangat Setuju (SS), diberi skor

$$
5
$$

b. Setuju (S), diberi skor 4

c. Netral/ragu-ragu $(\mathrm{N})$, diberi skor 3

d. Tidak Setuju (TS), diberi skor

$$
2
$$

e. Sangat Tidak Setuju (STS), diberi skor 1

Dengan cara perhitungan skor :

Jumlah Skor Tiap Kriterium = Capaian Skor $\mathrm{x}$ Jumlah Responden

Untuk : $\mathrm{S}_{5}=5$ x $68=340$

$$
\begin{aligned}
& S_{4}=4 \times 68=272 \\
& S_{3}=3 \times 68=204 \\
& S_{2}=2 \times 68=136 \\
& S_{1}=1 \times 68=68
\end{aligned}
$$

Jumlah skor ideal untuk setiap pernyataan (skor tertinggi $)=340$ (Sangat setuju $)$

Jumlah skor terendah $=36$ (Sangat tidak setuju) Dengan interpretasi nilai :

Cara perhitungan skor keseluruhan untuk mengetahui persepsi masyarakat terhadap program pengelolaan sampah secara $3 R$ :

Jumlah Skor Seluruh Kriterium = Capaian Jumlah Skor x Jumlah Responden x Jumlah pertanyaan

Untuk: $S_{5}=5 \times 68 \times 20=6800$

$$
\begin{aligned}
& S_{4}=4 \times 68 \times 20=5440 \\
& S_{3}=3 \times 68 \times 20=4080 \\
& S_{2}=2 \times 68 \times 20=2720 \\
& S_{1}=1 \times 68 \times 20=1360
\end{aligned}
$$

Jumlah skor ideal untuk keseluruhan pernyataan $($ Tertinggi $)=6800$

Jumlah skor Terendah $=1360$

Analisis data yang digunakan merupakan analisis deskriptif yang diukur dengan skala likert dimana menurut Riduwan (2015) adalah sebagai berikut:

Keterangan Kriteria Interpretasi Skor : Setuju

$$
\text { Angka 0\%-20\% = Sangat Tidak }
$$

Angka 21\%-40\% = Tidak Setuju

Angka $41 \%-60 \%=$ Netral

Angka $61 \%-80 \%=$ Setuju

Angka $81 \%-100 \%=$ Sangat Setuju 
Dalam penelitian ini, persepsi dibagi menjadi 3 kategori yaitu positif, netral, dan negatif. Persepsi positif berada di kriteria Setuju (S) dan Sangat Setuju (SS), persepsi netral di kriteria Netral $(\mathrm{N})$, dan persepsi negatif berada di kriteria Tidak Setuju dan Sangat Tidak Setuju.

\section{HASIL DAN PEMBAHASAN}

\section{Deskripsi Lokasi Penelitian}

\section{Letak Geografis dan Kondisi Umum}

Kelurahan Manembo-nembo Tengah merupakan salah satu kelurahan yang terletak di wilayah Kecamatan Matuari, Kota Bitung. Kelurahan Manembo-nembo Tengah terdiri dari 4 Lingkungan dan 17 RT. Secara geografis, Kelurahan Manembo-nembo Tengah berbatasan dengan kelurahan-kelurahan lainnya. Batasbatas wilayah kelurahan Manembo-nembo Tengah adalah sebagai berikut:

1. Sebelah Utara : Kelurahan Manembo-nembo Atas

2. Sebelah Selatan : Kelurahan Sagerat Weru Satu

3. Sebelah Timur : Kelurahan Manembo-nembo

4. Sebelah Barat : Kelurahan Manembo-nembo Atas

Kelurahan Manembo-nembo memiliki jarak 150 meter dari pusat pemerintahan kecamatan, 5 kilometer dari ibukota Kota, dan 45 kilometer dari ibukota Provinsi. Dilihat dari topografinya, kelurahan Manembo-nembo Tengah merupakan kawasan dataran rendah dengan tingkat kemiringan tanah $15^{\circ}$, suhu udara rata-rata $30^{\circ} \mathrm{C}$ dan memiliki luas wilayah $20 \mathrm{Ha} / \mathrm{m} 2$.

\section{Kependudukan}

Data tahun 2015, Kelurahan Manembonembo Tengah memiliki jumlah penduduk sebanyak 4.271 jiwa. Komposisi jumlah penduduk dari 2.124 orang laki-laki dan 2.147 orang perempuan. Jumlah Kepala Keluarga (KK) di Kelurahan Manembo-nembo Tengah adalah 4.271 KK. Berdasarkan usianya penduduk Kelurahan Manembo-nembo Tengah dikelompokan menjasi tiga kelompok yang secara rinci dapat dilihat pada Tabel 1.

Sumber : Data Primer Diolah, 2016

Jenis pekerjaan penduduk Kelurahan Manembo-nembo Tengah didominasi oleh Pegawai Negeri Sipil yaitu sebanyak 257 orang. Penjelasan terperinci mengenai jenis pekerjaan penduduk Kelurahan Manembo-nembo Tengah disajikan dalam Tabel 2.

\section{Sarana dan Prasarana Kebersihan}

Kelurahan Manembo-nembo Tengah adalah salah satu kelurahan di Kota Bitung yang turut berkomitmen untuk menangani masalah sampah. Data yang tercantum pada profil kelurahan tahun 2014 menunjukan bahwa Kelurahan Manembo-nembo Tengah telah meiliki sarana dan prasarana yang menunjang pengelolaan sampah. Rincian mengenai sarana dan prasarana tersebut disajikan dalam Tabel 2.

\section{Program Pengelolaan Sampah di Kelurahan Manembo-nembo Tengah}

Pemerintah Kota Bitung mencanangkan program pengelolaan sampah dengan prinsip $3 \mathrm{R}$ yaitu pengurangan sampah dilaksanakan melalui kegiatan daur ulang sampah, pengomposan dan Bank Sampah, serta kegiatan lain yang bertujuan untuk mengurangi sampah yang dihasilkan. Pemilahan sampah dikategorikan sampah organik dan anorganik.

\section{Deskripsi Responden}

\section{Usia Responden}

Responden dalam penelitian ini mencakup warga yang bertempat tinggal di Kelurahan Manembo-nembo Tengah yang terdiri dari berbagai tingkatan usia. Usia responden berkisar antara 21 tahun sampai dengan 76 tahun yang dikategorikan menjadi 6 kelompok. Secara terperinci karakteristik responden berdasarkan usia dapat dilihat pada Tabel 3.

Tabel 3 menunjukan bahwa sebagian besar responden dalam penelitian ini memiliki usia dalam kategori dewasa akhir yaitu sebesar $48.53 \%$, sedangkan responden 
denganpersentase terkecil $2.94 \%$ yaitu responden yang tergolong dalam kategori manula.

\section{Jenis Kelamin Responden}

Jenis kelamin responden dalam penelitian ini terdiri dari dua kategori yaitu lakilaki dan perempuan. Penjelasan terperinci mengenai sebaran responden berdasarkan jenis kelamin disajikan pada Tabel 4.

Sebagian besar responden berjenis kelamin perempuan dengan persentase sebesar $69.12 \%$ sedangkan responden berjenis kelamin laki-laki memiliki persentase sebesar 30.88\%.

\section{Pendidikan Responden}

Tingkat pendidikan responden dalam penelitian ini dibagi menjadi 4 kategori yang terdiri dari Sekolah Dasar (SD), Sekolah Lanjutan Tingkat Pertama (SLTP), Sekolah Lanjutan Tingkat Atas (SLTA), dan Perguruan Tinggi. Penjelasan terperinci mengenai tingkat pendidikan responden disajikan pada Tabel 5.

Tabel 5 menunjukan bahwa sebagian besar responden telah menempuh pendidikan SLTA yaitu sebanyak 49 orang denganpersentase sebesar 72.06\%. 20.59\% dengan tingkat pendidikan SLTP yaitu sebanyak 14 orang responden, sedangkan pada tingkat pendidikan Perguruan Tinggi sebanyak 4 orang responden denganpersentase $5.88 \%$ dan sisanya $1.47 \%$ hanya menempuh tingkat pendidikan SD yaitu 1 orang responden.

\section{Pekerjaan Responden}

Pekerjaan responden di Kelurahan Manembo-nembo Tengah beragam terdiri dari Pegawai Swasta, Pegawai Negeri Sipil (PNS), Mahasiswa, Ibu Rumah Tangga (IRT), Honorer dan Wiraswasta. Penjelasan terperinci mengenai karakteristik responden berdasarkan jenis pekerjaan disajikan pada Tabel 6 .

Tabel 6 menunjukan bahwa pekerjaan responden didominasi oleh Ibu Rumah Tangga yaitu sebesar $44.11 \%$, Pegawai Swasta $16.17 \%$, Wiraswasta $14.71 \%, 10.29 \%$ responden sebagai
PNS sedangkan mahasiswa $8.83 \%$ dan sisanya honorer yaitu ssebanyak $5.89 \%$.

\section{Persepsi Responden Terhadap Program Pengelolaan Sampah Secara Reduce, Reuse, Recycle (3R)}

Persepsi masyarakat terhadap program pengelolaan sampah secara $3 \mathrm{R}$ disini diteliti untuk melihat pandangan warga Kelurahan Manembo-nembo Tengah dalam menilai program pengelolaan sampah secara 3R. Dalam penelitian ini, persepsi terhadap program pengelolaan sampah secara $3 \mathrm{R}$ diukur dengan mengajukan pernyataan positif kepada responden. Untuk merespon pernyataan tersebut diberikan 5 pilihan respon yang terdiri dari Sangat Setuju (SS), Setuju (S), Netral (N), Tidak Setuju (TS) dan Sangat Tidak Setuju (STS).

Penjelasan terperinci mengenai persepsi masyarakat terhadap program pengelolaan sampah secara 3R disajikan sebagai berikut :

\section{Persepsi Responden Terhadap Sosialisasi Program Pengelolaan Sampah Secara 3R}

Pada Tabel 7 menunjukan bahwa materi yang dibawakan tentang TPST 3R mudah dimengerti memiliki indeks persepsi sebesar $55 \%$, sehingga nilai interpretasinya tergolong netral. Mengenai informasi penempatan TPST 3R memiliki indeks persepsi 58.52, sehingga nilai interpretasinya tergolong netral. Untuk informasi penempatan tempat sampah 2 warna memiliki indeks persepsi 55.88\% sehingga nilai interpretasinya tergolong netral. Dan dalam hal informasi terhadap bank sampah memiliki indeks persepsi $65.88 \%$, sehingga nilai interpretasinya tergolong setuju.

Interpretasi persepsi responden terhadap sosialisasi program pengelolaan sampah secara 3R disajikan sebagai berikut.

Interpretasi persepsi responden terhadap sosialisasi program pengelolaan sampah secara 3R adalah $58.82 \%$ dan tergolong kriteria netral. Sehingga persepsi responden terhadap sosialisasi program pengelolaan sampah dikategorikan persepsi netral.

Sosialisasi yang dilakukan pemerintah setempat yaitu dalam bentuk pemberian materi kepada masyarakat yang meliputi organisasi 
Pembinaan Kesejahteraan Keluarga (PKK), Ketua-ketua RT dan Kepala Lingkungan serta masyarakat setempat.

\section{Persepsi Responden Terhadap Sarana dan Prasarana Penunjang Program Pengelolaan Sampah Secara 3R}

Selain persepsi terhadap sosialisasi program pengelolaan sampah secara 3R, responden juga memiliki persepsi yang berbeda-beda terhadap Penyediaan sarana dan prasarana penunjang program pengelolaan sampah secara 3R. Lebih jelas mengenai persepsi responden terhadap penyediaan sarana dan prasarana disajikan dalam Tabel 8 .

Tabel 9 menunjukan bahwa pengadaan TPST 3R memberikan manfaat bagi lingkungan memiliki indeks persepsi sebesar $67.64 \%$, sehingga nilai interpretasinya tergolong setuju. Untuk lokasi TPST 3R di tempat strategis mendapatkan indeks persepsi sebesar $84.70 \%$ sehingga nilai interpretasinya tergolong sangat setuju. Mengenai TPST 3R memberikan motivasi kepada masyarakat dalam mengelolah sampah mendapatkan indeks persepsi sebesar $72.05 \%$, sehingga nilai interpretasinya tergolong setuju. Dan dalam hal pengadaan TPST 3R akan mengurangi volume sampah yang dibuang ke TPA memiliki indeks persepsi sebesar $70.88 \%$, sehingga nilai interpretasinya tergolong setuju.

Responden memiliki indeks persepsi sebesar $52.94 \%$ terhadap bentuk dan warna tempat sampah 2 warna, sehingga nilai interpretasinya tergolong netral. Mengenai ukuran tempat sampah 2 warna memiliki indeks persepsi $56.47 \%$, sehingga nilai interpretasinya tergolong netral. Sedangkan mengenai jumlah tempat sampah 2 warna memiliki indeks persepsi sebesar 52.64, sehingga nilai interpretasinya tergolong netral. Untuk lokasi tempat sampah 2 warna ditempat strategis mendapat indeks persepsi sebesar 55\%, sehingga nilai interpretasinya tergolong netral. Dan dalam hal adanya tempat sampah 2 warna memberikan kemudahan untuk membuang sampah memeliki indeks persepsi sebesar $52.94 \%$ dengan nilai interpretasinya tergolong netral.

Untuk program bank sampah, $72.05 \%$ indeks persepsi responden terhadap bank sampah memberikan manfaat bagi masyarakat dengan nilai interpretasinya tergolong setuju. Mengenai bank sampah membantu perbaikan kebersihan lingkungan memiliki indeks persepsi sebesar $73.52 \%$, sehingga nilai interpretasinya tergolong setuju. Dan mengenai bank sampah membantu mengurangi tumpukan sampah memiliki indeks persepsi sebesar 75.29 dengan nilai interpretasinya tergolong setuju. Interpretasi persepsi responden terhadap sarana dan prasarana penunjang program pengelolaan sampah secara 3R disajikan sebagai berikut.

\section{Persepsi Responden Terhadap Pemilahan, Pengomposan, dan Daur Ulang Sampah}

Responden memiliki persepsi yang berbeda-beda mengenai pemilahan, pengomposan dan daur ulang sampah. Untuk lebih jelas dapat dilihat pada Tabel 9 .

Tabel 9 menunjukan bahwa pemilahan sampah bermanfaat untuk kelestarian lingkungan hidup memiliki indeks persepsi sebesar $63.52 \%$ dengan nilai interpretasinya tergolong setuju. Mengenai pemilahan sampah memberikan manfaat bagi masyarakat memiliki indeks persepsi sebesar $62.64 \%$, sehingga nilai interpretasinya tergolong setuju. Untuk pengolahan sampah menjadi kompos memberikan manfaat bagi masyarakat memiliki indeks persepsi sebesar $58.52 \%$ dengan nilai interpretasinya tergolong netral. Sedangkan dalam hal pengolahan sampah menjadi kerajinan memberikan manfaat bagi masyarakat mendapatkan indeks persepsi $59.11 \%$, sehingga nilai interpretasinya tergolong netral.

Interpretasi persepsi responden terhadap pemilahan, pengomposan dan daur ulang sampah disajikan sebagai berikut.

Persepsi responden terhadap pemilahan, pengomposan dan daur ulang sampah memiliki nilai interpretasi $60.95 \%$ dan tergolong kriteria setuju. Sehingga persepsi responden terhadap pemilahan, pengomposan dan daur ulang sampah dikategorikan persepsi positif.

Proses Pemilahan Sampah di Kelurahan Manembo-nembo Tengah dimulai dari skala rumah tangga, yakni masyarakat melakukan pemilahan sampah organik (dedaunan dan sisasisa makanan) dan sampah anorganik (kertas, kardus dan sebagainya). Untuk kedua jenis sampah tersebut sudah disediakan tempat sampah 2 warna untuk menampungnya. Tempat 
sampah yang disediakan berwarna kuning dan hijau. Tempat sampah warna kuning untuk sampah kertas, kardus, tisu dan sebagainya, sedangkan tempat sampah warna hijau untuk sampah dedaunan dan sisa-sisa makanan. Sementara untuk sampah plastik dipilah diletakan di wadah (karung) yang sudah disediakan di depan rumah kemudian diangkut oleh petugas Bank Sampah dan dihargai Rp. $1000 / \mathrm{kg}$.

Pengolahan sampah menjadi kompos dilakukan oleh petugas Tempat Pengelolaan Sampah Terpadu (TPST 3R). Bahan baku pembuatan kompos berasal dari sisa-sisa dedaunan dan ranting pohon.

\section{Persepsi Responden Secara Keseluruhan}

Untuk mengetahui persepsi masyarakat terhadap program pengelolaan sampah secara
3R di Kelurahan Manembo-nembo Tengah secara keseluruhan dapat dihitung dengan cara membagi jumlah skor hasil penelitian dengan jumlah skor ideal (tertinggi) kemudian dikalikan dengan 100\%. Jumlah skor hasil penelitian ini adalah 4305 dan memiliki skor ideal yaitu 6800 didapat berdasarkan 20 pernyataan yang diajukan kepada 68 responden. Persepsi masyarakat secara keseluruhan disajikan sebagai berikut.

Interpretasi persepsi masyarakat secara keseluruhan adalah $63.30 \%$ dan termasuk kriteria setuju. Sehingga persepsi masyarakat terhadap program pengelolaan sampah secara 3R di Kelurahan Manembo-nembo Tengah, Kecamatan Matuari Kota Bitung tergolong persepsi positif.

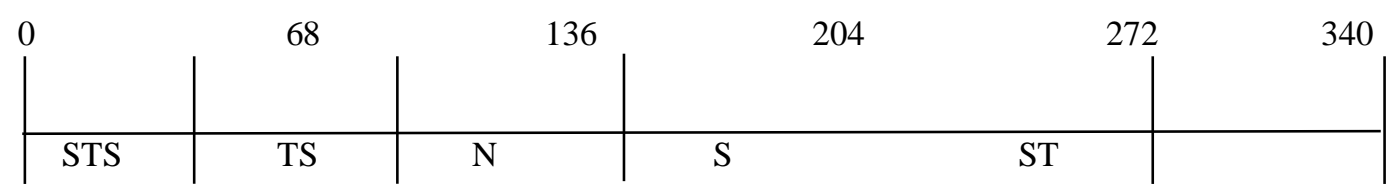

Persepsi Masyarakat $=\frac{\text { Jumlah Skor Hasil Pengumpulan Data }}{\text { Jumlah Skor Ideal }(\text { Tertinggi })} \times 100 \%$

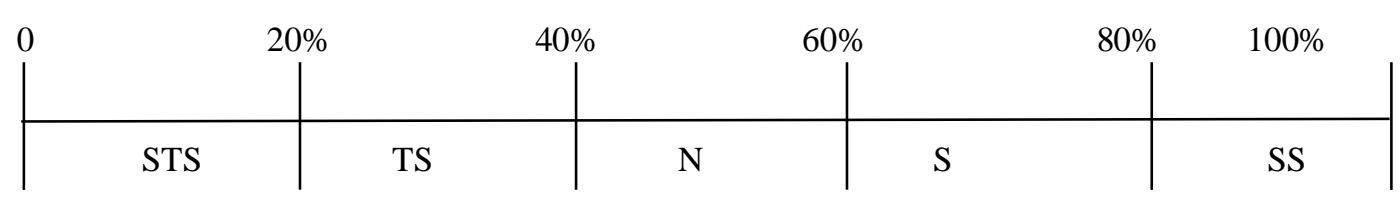

Tabel 1. Jumlah Penduduk Kelurahan Manembo-nembo Tengah Berdasarkan Usia

\begin{tabular}{ccccc}
\hline Usia (Tahun) & Laki-laki & $\begin{array}{c}\text { Persentase } \\
(\%)\end{array}$ & Perempuan & Persentase (\%) \\
\hline $1-14$ & 528 & 24.86 & 553 & \\
$15-64$ & 1579 & 74.34 & 1578 & 25.76 \\
$>64$ & 17 & 0.80 & 16 & 73.50 \\
\hline Jumlah & 2124 & 100 & 2147 & 0.74 \\
\hline
\end{tabular}


Tabel 2. Sarana Dan Prasarana Kebersihan Di Kelurahan Manembo-nembo Tengah

\begin{tabular}{lc}
\hline \multicolumn{1}{c}{ Sarana dan Prasarana Kebersihan } & Jumlah \\
\hline Tempat Pengelolaan Sampah Terpadu (TPST) 3R & 1 unit \\
Bank Sampah "PRO MIRAH” & 1 unit \\
Tempat Sampah (2 Warna) & 15 unit \\
Bak Sampah (3 Warna dan 5 Warna) & 4 lokasi \\
Tong Sampah & 65 unit \\
Tempat Pengomposan & 1 unit
\end{tabular}

Sumber : Data Primer Diolah, 2016

Tabel 3. Karakteristik Responden Berdasarkan Usia

\begin{tabular}{|c|c|c|}
\hline Usia (Tahun) & Jumlah (Orang) & Persentase (\%) \\
\hline 17-25 (remaja akhir) & 8 & 11.77 \\
\hline 26-35 (dewasa awal) & 9 & 13.23 \\
\hline 36-45 (dewasa akhir) & 33 & 48.53 \\
\hline 46-55 (lansia awal) & 13 & 19.12 \\
\hline 56-65 (lansia akhir) & 3 & 4.41 \\
\hline$>65$ (manula) & 2 & 2.94 \\
\hline Total & 68 & 100 \\
\hline
\end{tabular}

Sumber : Data Primer Diolah, 2016

Tabel 4. Karakteristik Responden Berdasarkan Jenis Kelamin

\begin{tabular}{|c|c|c|}
\hline Jenis Kelamin & Jumlah (Orang) & Persentase $(\%)$ \\
\hline Laki-laki & 21 & 30.88 \\
\hline Perempuan & 47 & 69.12 \\
\hline Total & 68 & 100 \\
\hline
\end{tabular}

Sumber : Data Primer Diolah, 2016 
Tabel 5. Karakteristik Responden Berdasarkan Tingkat Pendidikan

\begin{tabular}{|c|c|c|}
\hline Tingkat Pendidikan & Jumlah (Orang) & Persentase (\%) \\
\hline SD & 1 & 1.47 \\
\hline SLTP & 14 & 20.59 \\
\hline SLTA & 49 & 72.06 \\
\hline Perguruan Tinggi & 4 & 5.88 \\
\hline Total & 68 & 100 \\
\hline
\end{tabular}

Sumber : Data primer diolah, 2016

Tabel 6. Karakteristik Responden Berdasarakan Jenis Pekerjaan

\begin{tabular}{|c|c|c|}
\hline Jenis Pekerjaan & Jumlah (Orang) & Persentase (\%) \\
\hline Pegawai Swasta & 11 & 16.17 \\
\hline Mahasiswa & 6 & 8.83 \\
\hline Ibu Rumah Tangga & 30 & 44.11 \\
\hline PNS & 7 & 10.29 \\
\hline Wiraswasta & 10 & 14.71 \\
\hline Honorer & 4 & 5.89 \\
\hline Total & 68 & 100 \\
\hline
\end{tabular}

Sumber : Data Primer Diolah, 2016

Tabel 7. Rekapitulasi Persepsi Responden Terhadap Sosialisasi Program Pengelolaan Sampah Secara 3R

\begin{tabular}{llccc}
\hline No & \multicolumn{1}{c}{ Pernyataan } & $\begin{array}{l}\text { Total } \\
\text { Skor }\end{array}$ & Indeks Persepsi (\%) & Interpretasi \\
\hline $1 \quad \begin{array}{l}\text { Materi yang dibawakan tentang } \\
\text { TPST 3R mudah dimengerti }\end{array}$ & 187 & 55 & Netral \\
$2 \quad \begin{array}{l}\text { Penempatan TPST 3R } \\
\text { diinformasikan dengan baik }\end{array}$ & 199 & 58.52 & Netral \\
$3 \quad \begin{array}{l}\text { Penempatan tempat sampah 2 warna } \\
\text { diinformasikan dengan baik }\end{array}$ & 190 & 55.88 & Netral \\
$4 \quad \begin{array}{l}\text { Informasi terhadap program bank } \\
\text { sampah mudah dipahami }\end{array}$ & 224 & 65.88 & Setuju \\
\hline
\end{tabular}

Sumber : Data Primer Diolah, 2016 
$\begin{aligned} \text { Persepsi Responden } & =\frac{\mathbf{8 0 0}}{1360} \times 100 \% \\ & =58.82 \%\end{aligned}$

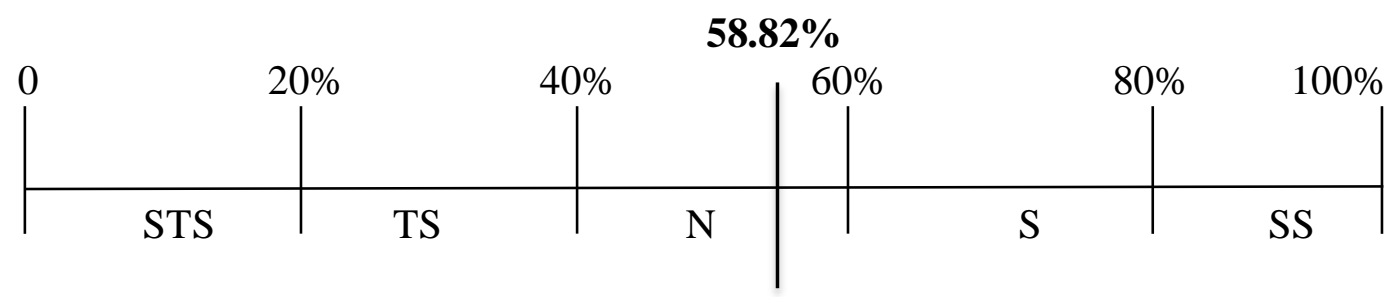

Tabel 8. Rekapitulasi Persepsi Responden Terhadap Penyediaan Sarana dan Prasarana

\begin{tabular}{|c|c|c|c|c|}
\hline $\begin{array}{l}\mathrm{N} \\
\mathrm{o}\end{array}$ & Pernyataan & $\begin{array}{l}\text { Total } \\
\text { Skor }\end{array}$ & $\begin{array}{c}\text { Indeks } \\
\text { Persepsi }(\%)\end{array}$ & Interpretasi \\
\hline 1 & $\begin{array}{l}\text { Pengadaan TPST 3R memberikan } \\
\text { manfaat bagi lingkungan hidup }\end{array}$ & 230 & 67.64 & Setuju \\
\hline 2 & Lokasi TPST 3R di tempat strategis & 288 & 84.70 & Sangat Setuju \\
\hline 3 & $\begin{array}{l}\text { TPST 3R memberikan motivasi } \\
\text { kepada masyarakat dalam } \\
\text { mengelolah sampah }\end{array}$ & 245 & 72.05 & Setuju \\
\hline 4 & $\begin{array}{l}\text { Pengadaan TPST } 3 \mathrm{R} \text { akan } \\
\text { mengurangi volume sampah yang } \\
\text { dibuang ke TPA }\end{array}$ & 241 & 70.88 & Setuju \\
\hline 5 & $\begin{array}{l}\text { Bentuk dan warna tempat sampah } \\
\text { sudah sesuai }\end{array}$ & 180 & 52.94 & Netral \\
\hline 6 & $\begin{array}{l}\text { Ukuran tempat sampah } 2 \text { warna } \\
\text { sudah sesuai }\end{array}$ & 192 & 56.47 & Netral \\
\hline 7 & $\begin{array}{l}\text { Jumlah tempat sampah } 2 \text { warna } \\
\text { sudah sesuai dengan kebutuhan } \\
\text { masyarakat }\end{array}$ & 179 & 52.64 & Netral \\
\hline 8 & $\begin{array}{l}\text { Lokasi tempat sampah } 2 \text { warna } \\
\text { ditempat strategis }\end{array}$ & 187 & 55 & Netral \\
\hline 9 & $\begin{array}{l}\text { Adanya tempat sampah } 2 \text { warna } \\
\text { memberikan kemudahan untuk } \\
\text { membuang sampah }\end{array}$ & 180 & 52.94 & Netral \\
\hline $\begin{array}{l}1 \\
0\end{array}$ & $\begin{array}{l}\text { Bank sampah memberikan manfaat } \\
\text { bagi masyarakat }\end{array}$ & 245 & 72.05 & Setuju \\
\hline $\begin{array}{l}1 \\
1\end{array}$ & $\begin{array}{l}\text { Bank sampah membantu perbaikan } \\
\text { kebersihan lingkungan }\end{array}$ & 250 & 73.52 & Setuju \\
\hline $\begin{array}{l}1 \\
2\end{array}$ & $\begin{array}{l}\text { Bank sampah membantu } \\
\text { mengurangi tumpukan sampah }\end{array}$ & 256 & 75.29 & Setuju \\
\hline
\end{tabular}

Sumber : Data Primer Diolah, 2016 

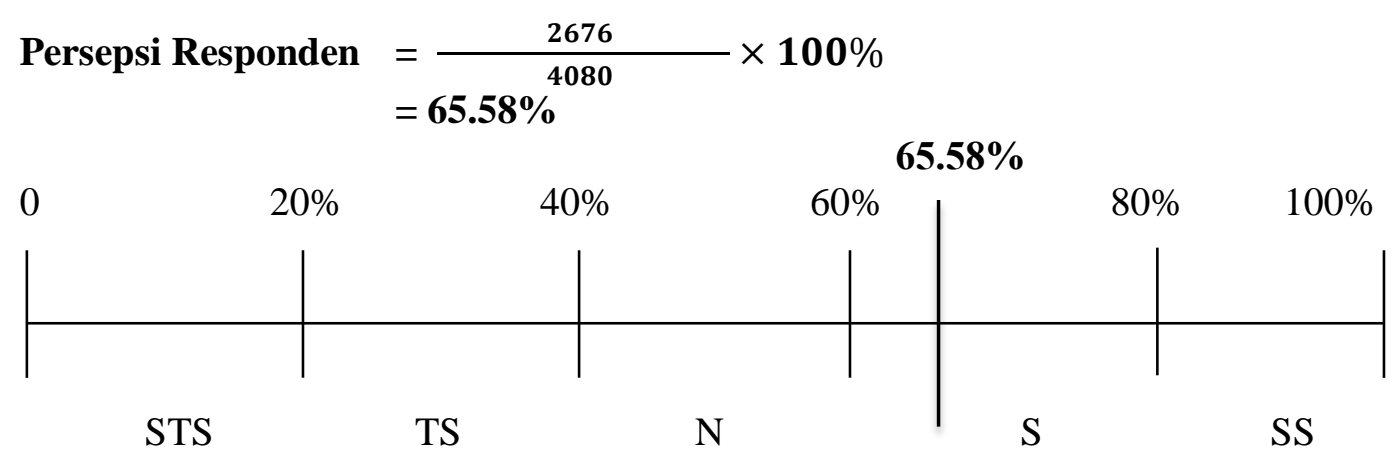

Tabel 9. Rekapitulasi Persepsi Responden Terhadap Pemilahan, Pengomposan, dan Daur Ulang Sampah

$\begin{array}{llll}\text { No } & \text { Pernyatan } & \text { Total } & \text { Indeks Persepsi (\%) }\end{array}$

1 Pemilahan sampah bermanfaat untuk kelestarian lingkungan hidup

2 Pemilahan sampah memberikan manfaat bagi masyarakat

$213 \quad 62.64 \quad$ Setuju

3 Pengolahan sampah menjadi kompos memberikan manfaat bagi masyarakat

$199 \quad 58.52 \quad$ Netral

4 Pengolahan sampah menjadi kerajinan memberikan manfaat bagi masyarkat
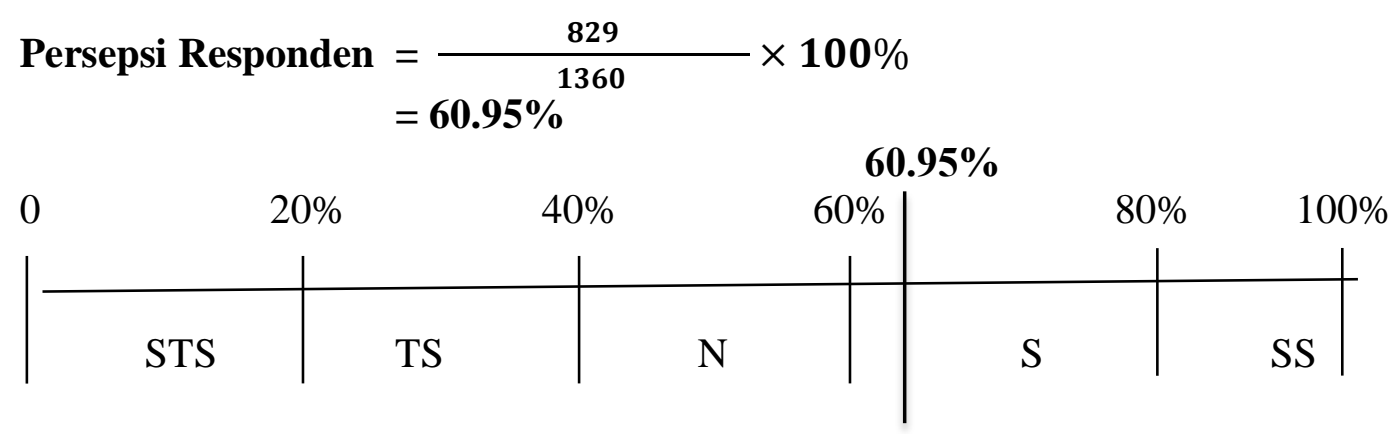
Tabel 10. Rekapitulasi Persepsi Responden Terhadap Program Pengelolaan Sampah Secara 3R

\begin{tabular}{clccc}
\hline No. & Pernyataan & $\begin{array}{c}\text { Jumlah } \\
\text { skor }\end{array}$ & $\begin{array}{c}\text { Indeks Persepsi } \\
(\%)\end{array}$ & Interpretasi \\
\hline $1 \quad$ & $\begin{array}{l}\text { Persepsi responden terhadap sosialisasi } \\
\text { program pengelolaan sampah secara 3R }\end{array}$ & 800 & 58.82 & Netral \\
& $\begin{array}{l}\text { Persepsi responden terhadap penyediaan } \\
\text { sarana dan prasarana penunjang program }\end{array}$ & 2676 & 65.58 & Setuju \\
& $\begin{array}{l}\text { Persepsi responden terhadap pemilahan, } \\
\text { pengomposan, dan daur ulang sampah }\end{array}$ & 829 & 60.95 & Setuju \\
& & & & \\
\hline
\end{tabular}

Sumber : Data primer diolah, 2016.

$\begin{aligned} \text { Persepsi Responden } & =\frac{4305}{6800} \times 100 \% \\ & =63.30 \%\end{aligned}$

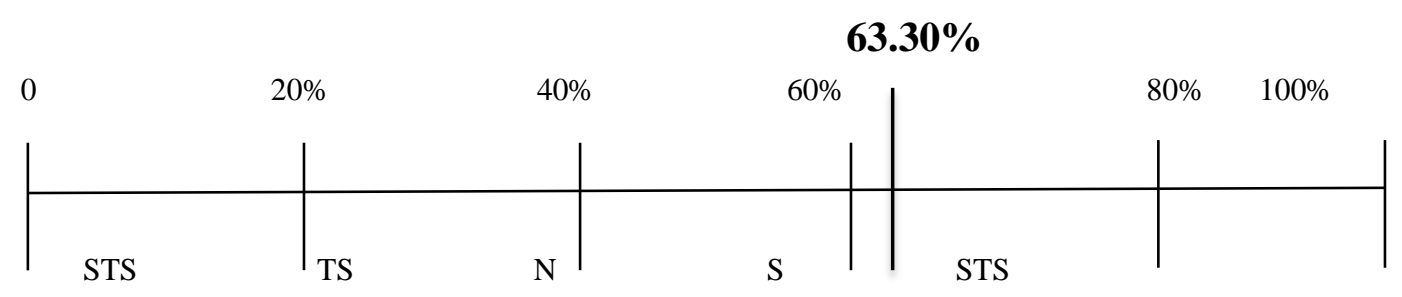




\title{
KESIMPULAN DAN SARAN
}

\section{Kesimpulan}

Persepsi masyarakat terhadap sosialisasi program pengelolaan sampah secara $3 \mathrm{R}$ masih tergolong netral, hal ini disebabkan kurangnya sosialisasi yang dilakukan pemerintah setempat, sedangkan persepsi masyarakat terhadap penyediaan sarana dan prasarana penunjang program adalah positif. Untuk persepsi masyarakat terhadap pemilahan, pengomposan, dan daur ulang sampah adalah positif. Sehingga sebagian besar masyarakat memiliki persepsi positif terhadap program pengelolaan sampah secara $3 \mathrm{R}$.

\begin{abstract}
Saran
Sosialisasi terhadap program pengelolaan sampah secara 3R harus lebih ditingkatkan. Penyediaan sarana dan prasarana lebih diperbanyak untuk beberapa lokasi. Dan pelatihan kepada masyarakat tentang pengomposan dan daur ulang sampah lebih ditingkatkan.
\end{abstract}

\section{DAFTAR PUSTAKA}

Anonim. 2011. Bank Sampah dan 3R: Membangun Lingkungan dan Ekonomi Kerakyaatan. Kementerian Lingkungan Hidup Republik Indonesia. Jakarta.

Chandra, B. 2006. Pengantar Kesehatan Lingkungan. EGC. Jakarta.

Sugiyono. 2012. Metode Penelitian Bisnis (Pendekatan Kuantitatif, Kulalitatif, dan R\&D). Alfabeta. Bandung.

Wangke, W. 2010. Persepsi Masyarakat Terhadap Kegiatan Pengembangan Lapangan UAP Dan PLTP Unit 5 Dan 6 PT Pertamina Geothermal Energy. Jurnal Agri-Sosioekonomi. Vol. 6, No. 3:39-44. 